\title{
Review
}

\section{Oncolytic herpes simplex virus vectors for cancer virotherapy}

\author{
Susan Varghese and Samuel D Rabkin
}

\author{
Molecular Neurosurgery Laboratory, Massachusetts General Hospital and Harvard Medical School, Charlestown, \\ Massachusetts 02129, USA.
}

Oncolytic herpes simplex virus type 1 (HSV-1) vectors are emerging as an effective and powerful therapeutic approach for cancer. Replication-competent HSV-1 vectors with mutations in genes that affect viral replication, neuropathogenicity, and immune evasiveness have been developed and tested for their safety and efficacy in a variety of mouse models. Evidence to-date following administration into the brain attests to their safety, an important observation in light of the neuropathogenicity of the virus. Phase I clinical traits of three vectors, G207, 1716, and NV1020, are either ongoing or completed, with no adverse events attributed to the virus. These and other HSV-1 vectors are effective against a myriad of solid tumors in mice, including glioma, melanoma, breast, prostate, colon, ovarian, and pancreatic cancer. Enhancement of activity was observed when HSV-1 vectors were used in combination with traditional therapies such as radiotherapy and chemotherapy, providing an attractive strategy to pursue in the clinic. Oncolytic HSV-1 vectors expressing "suicide" genes (thymidine kinase, cytosine deaminase, rat cytochrome P450) or immunostimulatory genes (IL-12, GM-CSF, etc.) have been constructed to maximize tumor destruction through multimodal therapeutic mechanisms. Further advances in virus delivery and tumor specificity should improve the likelihood for successful translation to the clinic.

Cancer Gene Therapy (2002) 9, 967-978 doi:10.1038/sj.cgt.7700537

Keywords: HSV; cancer therapy; clinical trials; oncolytic virus

\section{Replication-competent oncolytic herpes simplex virus (HSV) vectors}

Over the past decade, since the very first replicationcompetent oncolytic herpes virus was described in 1991 for the treatment of malignant gliomas, ${ }^{1}$ substantial progress has been made in exploiting the unique features of HSV type 1 as vectors for cancer therapy. This progress is amply demonstrated by the translation of three different HSV vectors to the clinic. ${ }^{2-4}$ The pertinent features that allowed HSV-1 to be used as vectors for cancer therapy are still key to the continued development of newer and more efficient vectors. HSV-1 is attractive for cancer therapy because of the following characteristics: (a) it infects a broad range of cell types and species; (b) it is cytolytic by nature (i.e., the replicative life cycle of the virus results in host cell destruction); (c) the wellcharacterized large genome (152 kb) contains many nonessential genes that can be replaced (up to $30 \mathrm{~kb}$ ) with multiple therapeutic transgenes; ${ }^{5}$ (d) a number of nonessential genes are associated with neurovirulence, ${ }^{6,7}$ (e) many

Received September 12, 2002.

Address correspondence and reprint requests to: Dr Samuel D Rabkin, MGH-East, 13th Street, Building 149, Box 17, Charlestown, MA 02129, USA.E-mail:rabkin@helix.mgh.harvard.edu antiherpetic drugs are available as a safeguard against unfavorable replication of the virus; ${ }^{8}$ and (f) the virus remains as an episome within the infected cell, even during latency, precluding insertional mutagenesis. ${ }^{9}$ These are distinct advantages over other viral vectors, such as adenovirus, retrovirus, and vaccinia virus. ${ }^{10}$

\section{First-generation, single-mutant HSV vectors}

One source of replication-competent HSV-1 vector selectivity for actively dividing cells, and hence cancer cells, is by virtue of mutations in viral enzymes involved in nucleotide metabolism (thymidine kinase [TK], ribonucleotide reductase $[\mathrm{RR}]$, and uracil deglycosylase $[\mathrm{UNG}]) .^{1{ }^{1-13}}$ There are functional similarities between the viral and cellular enzymes, which are up-regulated in cancer cells and not expressed for the most part in postmitotic cells. ${ }^{14-18}$ Early attempts to utilize HSV-1 as an oncolytic vector focused on mutating/deleting one of these genes, leading to the development of first-generation attenuated vectors (Table 1, Fig 1). The first HSV-1 vector genetically engineered for oncolytic therapy, $d l s p t k$, contained a deletion of the $T K$ gene and was targeted for brain tumor therapy. ${ }^{1}$ Athymic mice harboring intracerebral human malignant gliomas when treated with $d l s p t k$ survived longer, with complete cures seen in some treated animals. ${ }^{1}$ However, neurotoxicity at high viral titers and the insensitivity of this mutant to 
Table 1 Oncolytic HSV vectors used for cancer therapy

\begin{tabular}{|c|c|c|c|c|}
\hline Virus & HSV genes mutated & Transgenes & Features & References \\
\hline \multicolumn{5}{|l|}{ First-generation vectors } \\
\hline dlsptk & TK & & Tumor cell complementation & {$[1,116]$} \\
\hline dl8.36tk & TK & LacZ & $\begin{array}{l}\text { Tumor cell complementation } \\
\text { Track viral replication }\end{array}$ & {$[11]$} \\
\hline hrR3 & ICP6 & LacZ & $\begin{array}{l}\text { Tumor cell complementation } \\
\text { Track viral replication }\end{array}$ & {$[19,24]$} \\
\hline R3616 & $\gamma 34.5$ & & $\begin{array}{l}\text { Attenuated for neurovirulence } \\
\text { Reduced viral replication }\end{array}$ & {$[27,117,118]$} \\
\hline 1716 & $\gamma 34.5$ & & $\begin{array}{l}\text { Attenuated for neurovirulence } \\
\text { Reduced viral replication }\end{array}$ & {$[31,119]$} \\
\hline NV1020 (R7020) & UL24, UL56 & & $\begin{array}{l}\text { HSV }-1 / H S V-2 \text { intertypic recombinant } \\
\text { Vaccine strain }\end{array}$ & {$[34,35]$} \\
\hline \multicolumn{5}{|l|}{ Second-generation vectors } \\
\hline G207 (MGH-1) & ICP6, $\gamma 34.5$ & $\operatorname{LacZ}$ & $\begin{array}{l}\text { Tumor cell complementation } \\
\text { Attenuated for neurovirulence } \\
\text { Reduced viral replication } \\
\text { Track viral replication }\end{array}$ & {$[38]$} \\
\hline 3616 UB & UNG, $\gamma 34.5$ & LacZ & $\begin{array}{l}\text { Attenuated for neurovirulence } \\
\text { Tumor cell complementation } \\
\text { Reduced viral replication } \\
\text { Track viral replication }\end{array}$ & {$[120]$} \\
\hline SUP & $\gamma 34.5, I C P 47$ & & $\begin{array}{l}\text { Attenuated for neurovirulence } \\
\text { No down-regulation of } \mathrm{MHC} \text { class I } \\
\text { Enhanced replication }\end{array}$ & {$[78]$} \\
\hline NV1023 & UL56, ICP47 & LacZ & $\begin{array}{l}\text { No down-regulation of } \mathrm{MHC} \text { class I } \\
\text { Track viral replication }\end{array}$ & {$[74]$} \\
\hline \multicolumn{5}{|l|}{ Third-generation vectors } \\
\hline $\mathrm{G} 47 \Delta$ & ICP6, $\gamma 34.5$, ICP47 & LacZ & $\begin{array}{l}\text { Attenuated for neurovirulence } \\
\text { No down-regulation of } \mathrm{MHC} \text { class I } \\
\text { Enhanced replication } \\
\text { Tumor cell complementation } \\
\text { Track viral replication }\end{array}$ & {$[33]$} \\
\hline \multicolumn{5}{|l|}{ Transcriptionally targeted vectors } \\
\hline G92A & TK, US3, UL24 & $\begin{array}{l}\mathrm{LacZ} \\
A / b-I C P 4\end{array}$ & $\begin{array}{l}\text { Selectivity for hepatocellular carcinoma } \\
\text { Track viral replication } \\
\text { Insensitive to ACV, GCV }\end{array}$ & {$[79]$} \\
\hline d12.CALP & TK, US3, UL24 & $\begin{array}{l}\mathrm{LacZ} \\
\text { Cal-ICP4 }\end{array}$ & $\begin{array}{l}\text { Selectivity for soft tissue and bone tumors } \\
\text { Track viral replication } \\
\text { Insensitive to ACV, GCV }\end{array}$ & {$[83]$} \\
\hline Myb34.5 & ICP6 & Myb- $\gamma 34.5$ & $\begin{array}{l}\text { Selectivity for cycling tumor cells } \\
\text { Tumor cell complementation }\end{array}$ & {$[80]$} \\
\hline \multicolumn{5}{|l|}{ Transgene-expressing vectors } \\
\hline rRp450 & ICP6 & CYP2B1 & $\begin{array}{l}\text { Tumor cell complementation } \\
\text { Bystander effect of toxic metabolite CPA }\end{array}$ & {$[67]$} \\
\hline HSV1yCD & ICP6 & $\mathrm{CD}, A F P$ & $\begin{array}{l}\text { Tumor cell complementation } \\
\text { Bystander effect of toxic metabolite } 5 \text { - FU }\end{array}$ & {$[68]$} \\
\hline NV1042 & UL56, ICP47 & $\begin{array}{l}\mathrm{IL}-12 \\
\mathrm{LacZ}\end{array}$ & $\begin{array}{l}\mathrm{mlL}-12 \text { expression from } \alpha_{4} \text { promoter } \\
\text { No down-regulation of } \mathrm{MHC} \text { class I } \\
\text { Track viral replication }\end{array}$ & {$[74]$} \\
\hline NV1034 & UL56, ICP47 & $\begin{array}{l}\text { GM-CSF } \\
\mathrm{LacZ}\end{array}$ & $\begin{array}{l}\text { mGM-CSF expression from } \alpha_{4} \text { promoter } \\
\text { No down-regulation of MHC class I } \\
\text { Track viral replication }\end{array}$ & {$[74]$} \\
\hline R8306 & $\gamma 34.5$ & $\mathrm{IL}-4$ & $\mathrm{mlL}-4$ expression from egr -1 promoter & {$[121]$} \\
\hline R8308 & $\gamma 34.5$ & IL - 10 & mIL-10 expression from egr -1 promoter & {$[121]$} \\
\hline M002 & $\gamma 34.5$ & $\mathrm{IL}-12$ & $\mathrm{mlL}-12$ expression from egr -1 promoter & {$[76]$} \\
\hline JS1/ - (OncoVEX [GM-CSF]) & $\gamma 34.5, I C P 47$ & GM-CSF & $\begin{array}{l}\text { mGM-CSF expression from CMV promoter } \\
\text { No down-regulation of MHC class I }\end{array}$ & {$[122]$} \\
\hline
\end{tabular}

ACV, acyclovir; AFP, autofluorescence protein; Alb, albumin promoter/enhancer; Cal, calponin promoter; CD, yeast cytosine deaminase; CPA, cyclophosphamide; CYP2B1, rat cytochrome P450; 5-FU, 5 -fluorouracil; GCV, ganciclovir; LacZ, E. coli LacZ; myb, B-myb promoter. 


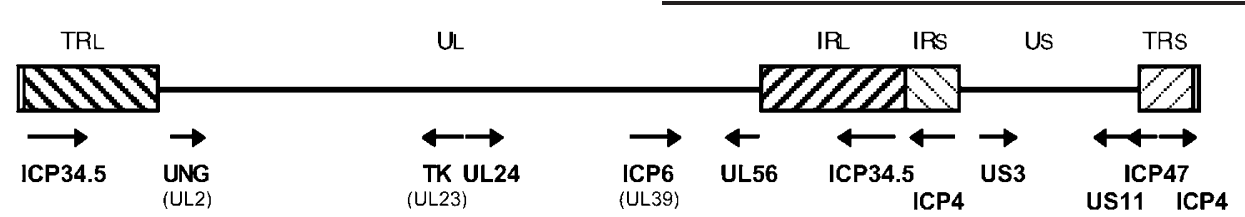

Figure 1 HSV DNA structure and schematic arrangement of genes mutated in the different oncolytic HSV vectors. The boxes represent the inverted repeat sequences (TR and IR) flanking the long ( $\mathrm{L}$ ) and short (S) unique regions. Arrows indicate the orientation and general position of the indicated transcripts.

antiherpes drugs, such as acyclovir (ACV) and ganciclovir (GCV), due to the absence of TK were major drawbacks to the clinical use of this vector. Nevertheless, the $d l s p t k$ mutant served as a proof-of-principle that attenuated mutants of HSV- 1 have therapeutic potential and formed the launching pad for further studies. The safety feature afforded by the presence of the $T K$ gene in HSV-1 mutants was important to the clinical application of these vectors to treat human cancers. Hence, the focus for further development of HSV- 1 vectors was directed at engineering viruses with mutations in other genes affecting virulence.

A RR-negative mutant, hrR3, with an in-frame insertion of the Escherichia coli LacZ gene into the ICP6 locus (Fig 1), was one such vector. ${ }^{19}$ The presence of $L a c Z$ provides an efficient mechanism to track viral infection and to distinguish the vector from patient isolates. ICP6 ${ }^{-}$mutants exhibit decreased neurovirulence ${ }^{20,21}$ and are hypersensitive to ACV and GCV. ${ }^{22,23}$ In experimental animal models, hrR3 was effective in treating malignant gliomas, prolonging survival times. ${ }^{24,25}$ Another set of HSV-1 vectors contains deletions in the $\gamma 34.5$ gene (Fig 1), the major viral determinant of neuropathogenicity. ${ }^{26,27}$ The $\gamma 34.5$ gene product blocks the shut-off of host cell protein synthesis induced by viral infection. ${ }^{28}$ Expression of this protein also facilitates viral replication in nondividing cells, such as adult neurons, contributing to the development of encephalitis. ${ }^{29,30}$ HSV- 1 $\gamma 34.5$ deletion mutants include 1716 , in strain $17^{+}, 31$ and $\mathrm{R} 3616$, in strain $\mathrm{F}^{27}$ both of which have been used successfully to treat a variety of animal tumor models. ${ }^{7}$ One potential drawback of $\gamma 34.5$ mutants is that they replicate less efficiently, with lower viral yields, as compared to wild-type virus. ${ }^{32,33}$

Another attenuated HSV-1 mutant currently being studied extensively for cancer therapy is NV1020 (previously known as R7020), in which the joint region of the long (L) and short (S) regions is deleted, including one copy of $\gamma 34.5$, UL24, and UL56. ${ }^{34,35}$ The deleted region was replaced with a fragment of HSV-2 US DNA (US2, US3 (PK), $g J$, and $g G$ ). This virus was originally developed as a herpes vaccine but was unsuccessful. However, building on the associated safety studies in rodents and primates, ${ }^{34,36}$ it has been used as an oncolytic agent against various non-CNS tumors (prostate, pancreatic, head and neck). ${ }^{35,37}$ These first-generation HSV-1 vectors, thus, provided the foundation for examining the critical issues of safety, specificity, and efficacy for oncolytic virotherapy.

\section{Second-generation, multimutated HSV vectors}

In order to maximize safety, it was reasoned that HSV-1 vectors developed for clinical application contain multiple mutations, so that virulent strains would not arise from reversion or second site suppressor mutations (Table 1). G207 was constructed as a second-generation vector from HSV - 1 laboratory strain F, with both copies of $\gamma 34.5$ deleted and the ICP 6 gene inactivated by insertion of the E. coli $\mathrm{LacZ}$ gene. ${ }^{38}$ Experimental testing of G207 in animal models for the treatment of malignant gliomas attested to its efficacy without compromising safety or specificity. ${ }^{38}$ Treatment of athymic mice, harboring established intracerebral or subcutaneous human U87MG gliomas, with a single intraneoplastic inoculation of G207 resulted in significant tumor regression prolonging their survival time. Following inoculation into tumors, G207 replicated preferentially in glioma cells but not in normal tissues, as monitored by histochemical detection of $\beta$-galactosidase ( $\mathrm{LaCZ}$ ) ${ }^{39}$ Although G207 was initially targeted for brain tumor therapy, experimental studies in vitro and in vivo showed that it was equally, if not more, effective against a wide variety of solid tumors, including melanoma, breast, colon, gallbladder, gastric, head and neck, ovarian, pancreatic, and prostate cancers. ${ }^{40}$ In syngeneic orthotopic bladder cancer and colon cancer metastatic to the liver models, G207 and NV1020 were equally effective. $^{41,42}$ Interestingly, in immune-competent mice, intraneoplastic inoculation of G207 into a local syngeneic tumor was found to induce systemic antitumor immunity, leading to the regression of a distant tumor and resistance to rechallenge with autologous tumor cells. ${ }^{43}$ Thus, G207 acts as an in situ cancer vaccine in these systems.

As data continued to accumulate regarding the antitumor efficacy of G207, preclinical toxicology studies were also conducted. Two animal models known for their exquisite sensitivity to HSV were chosen for safety testing: young BALB/c mice and Aotus nancymai, New World owl monkeys. As the natural tropism for HSV- 1 is the central nervous system, extensive toxicity evaluation was conducted after administration into the brain. In mice, doses of up to $1 \times 10^{7}$ plaque-forming units (pfu) of G207 inoculated into the brain (cerebrum or the ventricles), liver, or prostate or through intravenous delivery resulted in no adverse effects. ${ }^{44,45} \mathrm{G} 207$ was also inoculated into peripheral nerves without leading to any nerve damage, thereby demonstrating that it is a nerve-sparing virus. ${ }^{46}$ In Aotus monkeys, a dose as high as $1 \times 10^{9}$ pfu of G207 inoculated intracerebrally did not result in significant disease or pathology, whereas a dose of $1 \times 10^{3}$ pfu of parental strain $F$ caused encephalitis and serious morbidity within 5 days. ${ }^{47}$ Two of these G207inoculated animals were injected intraprostatically with G207 2 years later. ${ }^{45}$ In this study, $1 \times 10^{7}$ pfu of G207 was inoculated, either in the previously exposed or naïve monkeys, and did not result in any abnormalities or virus shedding. The analysis included histopathology of the brain, liver, lung, 
kidney, urogenital organs, etc.; PCR analysis of the various tissues for the presence of viral DNA; viral shedding; and blood analysis (differential and chemistry).

\section{Combination with conventional therapies}

In so far as the selection criterion for engineering replicationcompetent attenuated HSV-1 vectors is to target actively dividing cells, it is similar to conventional modes of cancer therapy such as chemotherapy and radiotherapy. However, with chemotherapy and radiotherapy, the narrow range of the therapeutic index, coupled with limiting high-dose toxicities, severely restricts their effectiveness. In contrast, viruses such as G207 have been efficacious in destroying tumors without toxicity to the host. ${ }^{40}$ Moreover, because tumors are typically heterogenous genetically and therapy selects for resistant phenotypes, no single agent is usually universally applicable or completely effective. The mode of action of HSV- 1 vectors, however, is different from that of standard therapies and is independent of many of the genotypic alterations, such as in p53, which are observed with chemotherapy or radiation-resistant tumors. ${ }^{48,49}$ Additionally, the maximal effect of replicating viruses should increase with time, whereas the peak activity of drugs declines with time. G207, NV1020, and 1716 have been tested in combination with standard chemotherapeutic agents ${ }^{50,51}$ or with ionizing radiation ${ }^{52-55}$ for augmentation of their individual efficacies.

The combined regimen of G207 and cisplatin was more effective $(100 \%$ cure $)$ than either cisplatin ( $14 \%$ cure $)$ or G207 alone (42\% cure) in treating cisplatin-sensitive human head and neck squamous cell carcinoma in an animal model. ${ }^{50}$ An additive efficacy was observed with 1716 and mitomycin $\mathrm{C}$ in a human lung cancer model. ${ }^{51}$ Ionizing radiation enhanced the lytic activity of NV1020 (R7020) in two separate models: human glioma ${ }^{53}$ and hepatoma ${ }^{54}$ xenografts in athymic mice. However, the effect in hepatoma was tumor cell-specific, in that the combined therapy had an effect on Hep3B but not on HuH7 tumors. ${ }^{54}$ The response with G207 and radiation is ambiguous; in one set of studies with human or syngeneic mouse prostate tumors, there was no enhanced efficacy with combination treatment, ${ }^{59}$ whereas in a cervical cancer model, increased efficacy was observed. ${ }^{55}$ The augmenting effects seen in the above combination modalities, likely based on the noninterfering activity of each agent, are very promising and have potential for immediate translation to the clinic.

Similar augmentation of efficacy has also been observed with oncolytic adenovirus vectors such as ONYX-015 (dl1520). The combination with cisplatin or 5-fluorouracil in mouse models was better than either agent alone. ${ }^{56}$ More importantly, clinical trials of ONYX-015 in combination with cisplatin and 5 -fluorouracil for head and neck cancer or metastatic colorectal cancer have provided encouraging results for this strategy. ${ }^{57,58}$ Interestingly, therapeutic doses of chemotherapy do not seem to inhibit the replication of any of the oncolytic viruses. The combination of ONYX-015 with radiation produced an additive antitumor effect in a radiation-sensitive, ONYX-015-sensitive, p53 mutant tumor cell line, but had no effect in the matched $\mathrm{p} 53$ wild-type, ONYX-015-resistant tumor cell line. ${ }^{60}$

\section{Modified oncolytic HSV vectors for enhanced activity or targeting}

Prodrug-activating HSV- 1 vectors

Strategies aimed at using prodrug-activating enzyme or "suicide" gene therapy initially focused on using the $H S V$ $T K$ gene to convert GCV into toxic metabolites ${ }^{61}$ (Table 1). The presence of TK in HSV-1 vectors imparts an inherent sensitivity to GCV such that both infected cellular and viral replications are blocked. However, this effect can be counterproductive to HSV-1 oncolytic therapy because it inhibits viral spread prematurely. The addition of GCV to hrR3 treatment of 9L tumor-bearing animals prolonged survival. ${ }^{25,62}$ However, in other experimental model systems, the combination of HSV-1 oncolysis and GCV treatment was not superior to HSV-1 oncolysis alone. ${ }^{63-66}$ Other prodrug-activating enzymes that have been utilized with oncolytic HSV-1 are rat cytochrome P450 (CYP2B1), which converts cyclophosphamide (CPA) to phosphoramide mustard (PM), ${ }^{67}$ and cytosine deaminase, which converts 5 fluorocytosine to 5 -fluorouracil ${ }^{68}$ (Table 1). Unlike GCV triphosphate, PM causes minimal inhibition of viral replication and can diffuse to neighboring cells. ${ }^{67} \mathrm{An}$ HSV-1 mutant, rRp450, carrying the CYP2B1 transgene inserted into the ICP 6 locus, exhibited enhanced efficacy in combination with CPA in suppressing the growth of subcutaneous glial tumors or diffuse liver tumors in rodents. ${ }^{67,69}$ However, expression of $C Y P 2 B 1$ in normal liver cells, where conversion of CPA could lead to toxic side effects, is a consideration against systemic use of this virus.

\section{Immunostimulatory $H S V-1$ vectors}

In immunocompetent animals, the therapeutic efficacy of oncolytic HSV-1 vectors appears to encompass two modes of action: direct cytotoxic activity of the virus itself and indirect induction of an antitumor immune response. This bimodal effect was demonstrated using bilateral syngeneic tumor models, where tumor growth inhibition occurred in both the virus-inoculated and noninoculated contralateral tumors. ${ }^{43,70}$ The antitumor immune response included a $\mathrm{CD}^{+} \mathrm{T}$-cell component generated against specific tumor cell antigens, ${ }^{43}$ and provided protection against rechallenge with a lethal dose of the same tumor cells. ${ }^{70}$ Thus, even as improvements are being made to enhance the lytic efficacy of the virus, efforts are also directed at promoting this antitumor immune response. Accordingly, many recombinant HSV vectors have been developed with the goal of exploiting the immune milieu around the tumor through genetically engineering HSV-1 either to abrogate viralinduced MHC class I down-regulation (by deletion of ICP47) or to deliver regulatory cytokines. Alternatively, oncolytic HSV vectors have been used as helper viruses for the generation of defective HSV vectors expressing immunomodulatory genes, such as $I L-2,{ }^{71} I L-12,{ }^{72}$ or soluble $B 7.1-I g{ }^{73}$ This latter strategy has certain advantages because the defective vector genome contains multiple copies of the transgene and cells infected by the defective vector alone will not be immediately killed as occurs after infection with the oncolytic vector. Among the recombinant vectors expressing cytokines, NV1034 and NV1042 are 
derivatives of NV1020, containing two additional insertions: the E. coli LacZ gene within ICP47 and either GM-CSF (NV1034) or mIL-12 (NV1042) $)^{74,75}$ (Table 1). Both GMCSF and IL - 12 were produced, respectively, by NV1034- or NV1042-infected murine squamous cell carcinomas in vivo; however, NV1042 was much more effective at inhibiting tumor growth. ${ }^{74}$ Another IL-12-expressing HSV-1 vector, M002, derived from the $\gamma 34.5$ deletion mutant R3659, exhibited increased efficacy against murine brain tumors, with a significant infiltration of $\mathrm{CD} 4^{+}$and $\mathrm{CD} 8^{+} \mathrm{T}$ cells and macrophages. $^{76}$

G47 $\Delta$ is a third-generation vector that was constructed from G207 by deletion of the ICP47 gene (Fig 1), which normally blocks MHC class I-mediated antigen presentation in infected cells ${ }^{33}$ (Table 1). Consequently, human melanoma cells infected with G47 $\Delta$ expressed higher levels of MHC class I on their surface, compared to G207-infected cells, resulting in enhanced stimulation of tumor-infiltrating lymphocytes. The ICP47 deletion also removes the US11 promoter, so that the late US11 gene is expressed as an immediate-early gene under the control of the ICP47 promoter, thereby suppressing the diminished growth properties of $\gamma 34.5$ mutants. ${ }^{77}$ This improved replication of G47 $\Delta$ translates into enhanced antitumor activity. ${ }^{33,78}$

\section{Transcriptionally targeted vectors}

Targeting the replication of oncolytic viruses to the tumor is essential for maximal benefit, especially when delivered systemically. To date, two strategies have been employed to target viral replication: the use of a tumor tissue-specific promoter/enhancer to drive expression of the essential immediate-early gene $I C P 4^{79}$ (replication-conditional vectors), or to express $\gamma 34.5^{80}$ to enhance replication in a fashion complementary to the ICP47 deletion (Table 1). Myb34.5, a transcriptionally potentiated vector, is derived from the $\gamma 34.5$ deletion mutant, MGH-1, by insertion of an exogenous $\gamma 34.5$ transgene driven by the E2F-responsive B- $m y b$ promoter into the ICP 6 locus. ${ }^{80}$ Therefore, it would be expected to target cycling cancer cells and also replicate more efficiently than the $\gamma 34.5$-deleted parental virus.
Myb34.5 was more efficacious than MGH-1 after intratumoral injection of subcutaneous gliomas or intravascular delivery to liver metastases. ${ }^{80,81}$ However, safety was partially compromised compared to $\gamma 34.5$ mutants.

G92A was the first example of a transcriptionally targeted HSV vector, where the albumin enhancer/promoter driving ICP4 was used to specifically target hepatocellular carcinomas. ${ }^{79}$ The specificity of G92A was demonstrated in vitro and in vivo where it selectively inhibited the growth of subcutaneous human Hep3B hepatoma tumors but not human $\mathrm{PC} 3$ prostate tumors. ${ }^{82}$ Importantly, intrahepatic delivery of G92A ( $T K^{-}$and $U S 3^{-}$) did not result in toxicity in the liver, as opposed to wild-type KOS virus, indicating the sparing of normal tissue by G92A virus. ${ }^{82}$ More recently, another ICP4-driven vector, $d$ l2.CALP, has been generated using the calponin promoter to drive HSV replication in soft tissue and bone tumors. ${ }^{83} \mathrm{~A}$ similar transcriptionally regulated replication strategy has been described for adenovirus vectors, termed CRAd (conditionally replicative adenovirus) or ARCA (attenuated, replication-competent adenovirus). Specificity has been achieved using multiple tissue - or tumor-specific promoters (i.e., $\alpha$-fetoprotein, kallikrein, Lplastin, midkine, prostate-specific antigen, tyrosinase) to regulate the expression of early genes $E 1 A$ or $E 1 B .{ }^{84,85}$ These CRAd vectors have also been used in combination with standard therapies such as chemotherapy and radiation. In a limited number of studies so far, the combinations have synergistically enhanced oncolytic activity. ${ }^{86-88}$

\section{Clinical trials}

Successful preclinical efficacy and safety studies have facilitated the launching of three oncolytic HSV-1 vectors into clinical trials: G207, 1716, and NV1020 (Table 2). Phase I clinical trials with G207, conducted in the US (Georgetown University and University of Alabama at Birmingham), and 1716, conducted in the UK (University of Glasgow), have been completed and were published in parallel in $2000 .^{2,3}$ In both cases, patients with recurrent malignant glioma, refractory to conventional treatments of

Table 2 Oncolytic HSV vectors in clinical trial

\begin{tabular}{|c|c|c|c|c|c|}
\hline Virus & Disease (patient number) & Delivery & Maximum dose (pfu) & Comments & References \\
\hline G207 & Recurrent glioma (21) & Intratumoral & $3 \times 10^{9}$ & $\begin{array}{l}\text { Safety confirmed } \\
\text { MRI volume decrease in eight patients } \\
\text { Two patients alive over } 4 \text { years }\end{array}$ & [2] \\
\hline \multirow{4}{*}{1716} & Recurrent glioma & Intratumoral, resection bed & & Ongoing trial & \\
\hline & Recurrent glioma (9) & Intratumoral & $1 \times 10^{5}$ & $\begin{array}{l}\text { Safety confirmed } \\
\text { Four patients alive over } 14 \text { months }\end{array}$ & [3] \\
\hline & HGG (12) & Intratumoral & $1 \times 10^{5}$ & $\begin{array}{l}\text { Safety confirmed } \\
\text { Evidence for viral replication }\end{array}$ & [89] \\
\hline & Melanoma (5) & Intralesional & $4 \times 10^{3}$ & $\begin{array}{l}\text { IHC evidence of viral replication } \\
\text { Some tumor necrosis }\end{array}$ & {$[90]$} \\
\hline NV1020 & $\begin{array}{l}\text { Hepatic metastatic } \\
\text { colorectal cancer (9) }\end{array}$ & Hepatic artery & $1.3 \times 10^{7}$ & $\begin{array}{l}\text { Decrease in CEA } \\
\text { MTD not reached } \\
\text { Ongoing trial }\end{array}$ & [4] \\
\hline
\end{tabular}

CEA, carcinoembryonic antigen; HGG, high-grade glioma; IHC, immunohistochemistry; MRI, magnetic resonance imaging; MTD, maximum tolerated dose. 
radiation and chemotherapy, were treated. A dose-escalating phase I clinical trial with NV1020 is ongoing for colorectal liver metastases, with the virus administered through the hepatic artery. ${ }^{4}$ Recently, BioVex has obtained approval to initiate a phase I clinical trial of OncoVEX(GM-CSF), a $\gamma 34.5$ deletion vector expressing GM-CSF (Table 1), for the treatment of solid tumors. Currently, clinical trials are conducted on patients with advanced forms of disease, so that long-term safety assessments are not completely available. Nonetheless, the results so far from all the clinical trials have been very promising, with no evidence of serious toxicity attributable to the virus while demonstrating anecdotal evidence of efficacy.

\section{G207 clinical trials}

The G207 phase I trial included 21 patients who received doses ranging from $1 \times 10^{6}$ to $3 \times 10^{8}$ pfu in $0.1 \mathrm{~mL}$ and $1 \times 10^{9} \mathrm{pfu}$ in $0.3 \mathrm{~mL}$ at a single site with a final cohort receiving $3 \times 10^{9} \mathrm{pfu}$ inoculated at five sites $(0.2 \mathrm{~mL}$ each $){ }^{2}$ Three patients were enrolled per dose and the virus was administered stereotactically to a contrast-enhancing region of the tumor (Fig 2). All of the patients tolerated G207 without any serious adverse events attributable to the virus. No viral shedding was detected, but G207 DNA was detected by PCR analysis in two of seven patients who underwent brain tumor biopsy (56 and 157 days posttreatment). The presence of viral DNA at these later times after virus inoculation is likely due to "latently" or nonproductively infected cells. Of the five patients who were HSV-1seronegative prior to G207 inoculation, one patient seroconverted. $^{2}$ Interestingly, eight patients exhibited radiographic reduction in tumor volume from 4 days to 1 month postinoculation. Two patients are still alive over 4 years after treatment and one patient who died from a cerebral

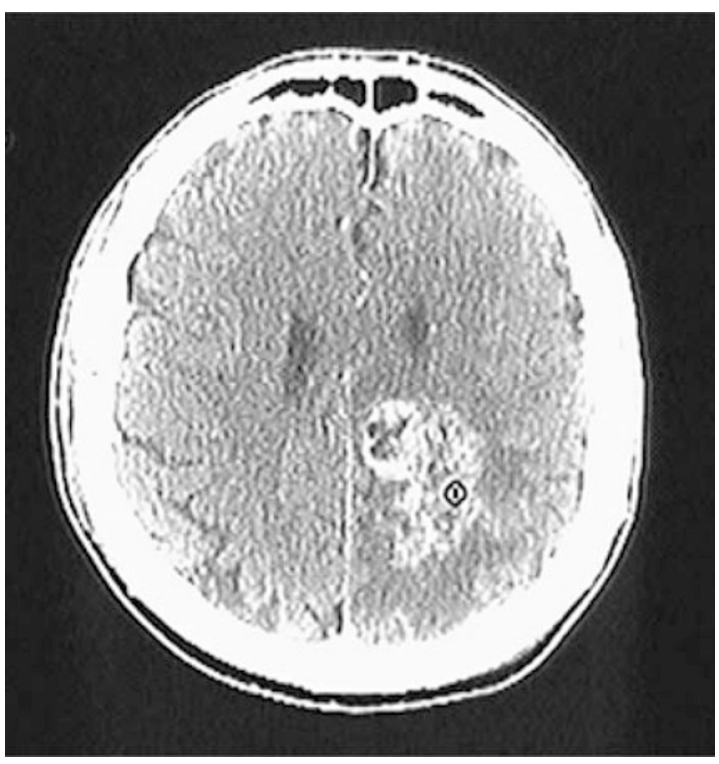

Figure 2 Axial contrast-enhanced computed tomography (CT) scan of patient's glioma prior to G207 injection. The target site for stereotactic injection is within an enhancing region of the tumor, as indicated $(\diamond)$. Photo courtesy of T Mineta. infarction (unrelated to treatment) at 10 months posttreatment did not show any evidence of residual tumor mass at autopsy. ${ }^{2}$ None of the patients who died displayed any signs of encephalitis during postmortem analysis. G207 is currently in a phase Ib trial where G207 is inoculated into the tumor and then, 2 days later, the tumor is resected and the tumor bed is inoculated. The resected tumor will then be analyzed for evidence of viral replication. A planned phase II trial will involve delivery to the tumor bed after tumor resection in order to improve distribution of the virus and decrease the tumor mass that needs to be destroyed. As the current standard of care for malignant glioma patients is ineffective, clinical trials in patients with newly diagnosed glioma, as opposed to recurrent, previously treated disease are a possibility. These patients are more likely to experience positive clinical outcomes from HSV therapy.

\section{6 clinical trials}

The 1716 trial tested a lower dose range $\left(1 \times 10^{3}-1 \times 10^{5}\right.$ pfu) in nine patients with recurrent gliomas ${ }^{3}$ (Table 2 ). Patient selection criteria were similar to the G207 trial; however, virus delivery was different with multiple injections of a $1-\mathrm{mL}$ total volume. No virus was detected by PCR in five patients and none exhibited any adverse events. Promisingly, four patients were alive over 14 months after treatment. Recently, a second trial of 1716 for malignant glioma was reported. ${ }^{89}$ Twelve patients with high-grade glioma (HGG) were enrolled, of which all, except for one, had recurrent tumors. Patients were injected intratumorally with $1 \times 10^{5}$ pfu 1716 , following which the tumor was surgically resected after 4-9 days. Viral replication was demonstrated by recovery of infectious virus (two patients) at levels higher than were inoculated, detection of significant amounts of viral DNA by PCR (10 patients), and immunohistochemical staining for HSV antigens (two patients), including against $U L 42$, an early gene product not present in virions. ${ }^{89}$ Interestingly, both seronegative patients seroconverted after treatment and their tumors stained positive for HSV antigens. Unfortunately, they died due to tumor progression within 9 months of treatment. As in the first trial, no adverse events were noted in any of the patients following 1716 injection. ${ }^{89} 1716$ has also been clinically tested in five patients with stage 4 melanoma, with each patient receiving between one and four injections of $1 \times 10^{3}$ pfu into a single nodule. ${ }^{90}$ In the three patients receiving multiple injections, there was histopathological evidence of tumor necrosis and HSV antigen was detected immunohistochemically only in tumor cells.

\section{Key hurdles}

Drawing an analogy to putting a man on the moon, French Anderson noted, "NASA can draw pictures of a spacecraft, with rocket engines and a capsule containing astronauts, going from earth to the moon. But in fact, there are hundreds of critical steps... Just having sufficiently powerful rocket engines is not enough... ${ }^{91}$ " The encouraging results from the clinical trials with oncolytic HSV vectors offer concrete proof that at least some of the past limitations have become 
today's possibilities and that the introduction of replicationcompetent HSV into humans can be performed safely. Nonetheless, major hurdles will have to be conquered before this form of therapy attains the status of conventional therapy. The limitations in using oncolytic HSV vectors for cancer therapy include some that are unique to HSV and some that apply to all replicating vectors; the discussion herein will emphasize the former.

\section{Virus delivery}

Most initial studies testing efficacy of HSV-1 vectors were conducted by administering the virus intratumorally. Easily accessible solid tumors are amenable to intratumoral delivery, but this approach is of limited value for those tumors that are not easily accessible, or for metastatic tumors. Multiple routes of oncolytic HSV-1 administration have been tested and found to be effective in animal models, including intravenous, ${ }^{92}$ intra-arterial, ${ }^{93}$ lymphatic, ${ }^{94}$ intraperitoneal, ${ }^{95}$ and local vascular perfusion. ${ }^{96}$ Whereas additional safety studies will be needed to evaluate these different routes of delivery, so far, the efficacy and lack of toxicity attest to the potential for systemic delivery of oncolytic HSV vectors for virotherapy. Nevertheless, further improvements are required to optimize effective tumor targeting. Rapid inactivation of the virus due to instability (virus half-lives), adsorption, and homing to nonspecific cells; clearing by the liver; innate immunity; preexisting immunity (antibodies) leading to complement-mediated inactivation; and lack of tropism are issues that merit continued research. Increasing the input dose is one way to overcome vector losses during delivery; however, with current manufacturing processes, attainable titers for oncolytic HSV vectors are $\sim 3 \times 10^{9} \mathrm{pfu} /$ $\mathrm{mL}$. Therefore, it is unlikely that patients will receive doses in excess of $10^{10} \mathrm{pfu}$, as opposed to conditionally replicating adenovirus, which has been used at doses of $10^{11}$ pfu or higher. ${ }^{58,97,98}$ Assault by host factors on the virus could be minimized by developing "Trojan horse" vectors, which could include the use of novel technologies, such as the use of cell carriers" ${ }^{99}$ or chemical "coating" to deliver viruses. Alternatively, the host can be modified by transient suppression of immunity during virus dispensation, ${ }^{93}$ or by administering virus premixed with complement inhibitory agents (e.g., dextran sulphate ${ }^{100}$ ), etc. Preexisting antibody to HSV is an important consideration as the majority of the human population are seropositive; however, studies in animal models demonstrate that prior immunity does not significantly interfere with therapeutic efficacy. ${ }^{42,101-103} \mathrm{On}$ the other hand, general immunosuppression induced by corticosteroid administration was found to reduce the rate of tumor cures. ${ }^{104}$ In contrast to HSV, preexisting antibodies to adenovirus have been shown to abrogate the antitumor activity of prostate cancer-specific adenovirus. ${ }^{105}$

\section{Tissue/tumor specificity}

Efforts are being made to alter the tropism of HSV to specific tumor tissues. Two strategies that need not be mutually exclusive could be envisioned: (a) altering the tropism of the virus by modifying viral receptors to bind specific tumor cell surface molecules, ${ }^{106}$ as has been done with adenovirus vectors; ${ }^{107}$ and (b) targeting viral replication within tumor cells using tumor- or tissue-specific promoter elements. Altering viral tropism for a large virus like HSV with multiple essential glycoproteins involved in interactions with various cell surface molecules will be difficult, as illustrated by the initial unsuccessful attempt using erythropoietin. ${ }^{108}$ This is in contrast to adenovirus where great advances have been made in developing viral vectors with modifications to the viral coat proteins. ${ }^{107}$ The second strategy of targeting replication within tumor cells, as with G92A virus, has already been discussed. As novel tumor-associated genes and their control elements are discovered, HSV-1 vectors can be designed to replicate selectively in these tissues. If high specificity can be achieved, it should be possible to use less attenuated mutants or even wild-type HSV as a backbone to express the tumor-regulated transgene.

\section{Viral replication and spread within the tumor}

A major benefit of using replication-competent vectors over defective vectors is the amplification of the input dose within the tumor. The rate of viral replication, however, is dependent on many factors including, the rate of tumor growth and the cellular environment. Targeting tumor cell physiology is a likely way to enhance oncolytic activity. ${ }^{109}$ Alterations in the ras pathway and interferon signaling have provided tumor selectivity for oncolytic reovirus, ${ }^{110}$ vesicular stomatitis virus, ${ }^{111,112}$ and influenza A mutants. ${ }^{113}$ For viruses deleted/mutated in genes involved in nucleotide metabolism (i.e., RR, TK), one could transiently increase expression of the complementing cellular enzymes, ${ }^{16}$ thereby enhancing viral replication. Conversely, a virus strain conditioned to grow in tissue culture in rapidly dividing cells and enriched growth conditions may not replicate as well in a tumor in vivo.

Suboptimal spread of the inoculated and newly replicated virus resulting in partial responses is a major challenge with HSV -1 vectors. During the early phases of viral infection, physical barriers play a major role, but with time, both physical and immune barriers restrict the efficient spread of the virus within a solid tumor. Extracellular matrix changes, tight gap junctions, fibrosis, and necrotic regions commonly observed in solid tumors could potentially limit viral spread. The development of syncytial viruses ${ }^{114}$ and viruses that express enzymes that break down extracellular matrix are options to consider in order to overcome this problem. A second determinant in the efficient spread of virus is antiviral immunity. Innate or acquired, preexisting or induced, immunity would result in immune-mediated clearance of the virus before its effect can be realized. In this regard, viruses that spread predominantly cell-to-cell rather than those that are released would not be affected by neutralizing antibody. When using immunostimulatory vectors, it can be expected that an enhanced immune response will be generated against both the virus and tumor. Ideally, it would be beneficial to generate minimal immune responses against the virus, and hence, methods to skew the response in favor of the tumor are worth considering. It is also important to develop vectors that promote long-term "memory" against 
tumors, as demonstrated with G207, where it acts as an in situ tumor vaccine. ${ }^{70}$

\section{Combination therapies}

As the mechanisms of action of therapeutic viruses are distinct from chemo - or radiotherapeutic agents, additive or synergistic responses are to be expected. Possible concerns about the combination of oncolytic HSV-1 vectors with traditional therapies are that the two might be interfering or that the combination would increase toxicity to normal tissue. For example, the extensive necrosis caused by chemotherapy or radiation could physically limit virus spread or induce an inflammatory response limiting virus spread. The importance of timing in combination therapy was demonstrated with adenovirus vector, ONYX-015, and cisplatin, where maximal efficacy was observed when cisplatin was administered concomitantly with, or subsequent to but not prior to, virus inoculation. ${ }^{115}$

\section{Viral toxicity/safety}

To date, the oncolytic HSV vectors have had an excellent safety profile both preclinically and clinically. Nevertheless, as more virulent vectors are created, similar preclinical evaluations will have to be conducted in appropriate animal models to ensure that the increased efficacy is not at the cost of safety. A distinct advantage of HSV is the availability of sensitive animal models (BALB/c or A/J mice, and the New World owl monkey, A. nancymai) that mimic the susceptibility pattern of humans to HSV-1. Safety evaluations should consider reversion to or acquiring virulent phenotypes, novel or previously unrecognized toxicity due to altered tropism or transgene expression, multiple dose-induced inflammatory responses, etc. The immunostimulatory viruses, expressing specific cytokines (IL-12, GM-CSF, etc.), might be expected to alter the host immunoregulatory balance in a haplotype-specific fashion. Hence, toxicological evaluations of these immune-enhanced viruses should be conducted in multiple strains of mice. Moreover, the ectopic overexpression of cytokines in normal tissues might lead to inflammatory responses to selfantigens and, therefore, autoimmunity.

\section{Summary}

Oncolytic HSV-1 vectors have proven in a relatively short span of time to be valuable tools for cancer therapy. As the first genetically engineered virus developed for virotherapy, ${ }^{1}$ HSV vectors have served as a prototype for the development of other oncolytic viruses. In animal models, oncolytic HSV vectors have proven to be both safe and efficacious through various routes of delivery, including systemic, which is essential for treating advanced metastatic disease. Their efficacy has been enhanced both by direct manipulation of the viral genome and expression of transgenes with cytocidal or immunomodulatory functions. Synergistic and/or additive effects of oncolytic HSV-1 have also been demonstrated in combination with conventional modes of therapy, such as chemotherapy and radiation. The phase I clinical trials are beginning to validate the preclinical safety studies while also providing a glimmer of efficacy. Many hurdles remain before this strategy becomes a standard therapeutic reality; however, the studies to date provide ample optimism.

\section{Acknowledgments}

We would like to thank the past and current members of the laboratory who have contributed to this research, in particular RL Martuza and T Todo for their invaluable assistance and insight. SD Rabkin is a member of the Scientific Advisory Board of MediGene, which has a license from Georgetown University for G207 and other vectors. This research has been supported, in part, by grants from the National Institutes of Health (NS32677, NS33342), Department of Defense (DAMD17-99-19202, DAMD17-98-1-8490), and CaPCURE Foundation (Santa Monica, CA).

\section{References}

1. Martuza RL, Malick A, Markert JM, et al. Experimental therapy of human glioma by means of a genetically engineered virus mutant. Science. 1991;252:854-856.

2. Markert JM, Medlock MD, Rabkin SD, et al. Conditionally replicating herpes simplex virus mutant, G207 for the treatment of malignant glioma: results of a phase I trial. Gene Ther. 2000;7:867-874.

3. Rampling R, Cruickshank G, Papanastassiou V, et al. Toxicity evaluation of replication-competent herpes simplex virus (ICP 34.5 null mutant 1716) in patients with recurrent malignant glioma [see comments]. Gene Ther. 2000;7:859-866.

4. Fong Y, Kemeny N, Jarnagin W, et al. Phase 1 study of a replication-competent herpes simplex oncolytic virus for treatment of hepatic colorectal metastases. Am Soc Clin Oncol Ann Meeting. 2002:27.

5. Roizman B. The function of herpes simplex virus genes: a primer for genetic engineering of novel vectors. Proc Natl Acad Sci USA. 1996;93:11307-11312.

6. Nishiyama Y. Herpesvirus genes: molecular basis of viral replication and pathogenicity. Nagoya J Med Sci. 1996;59: $107-119$.

7. Rabkin SD, Hernaiz Driever P. Replication-competent herpes simplex virus vectors for cancer therapy. In: Rabkin SD, Hernaiz Driever P, eds. Replication-Competent Viruses for Cancer Therapy. Monographs in Virology. Basel: Karger; 2001;vol. 22:1-45.

8. Balfour HH Jr. Antiviral drugs. N Engl J Med. 1999;340: $1255-1268$.

9. Mellerick DM, Fraser NW. Physical state of the latent herpes simplex virus genome in a mouse model system: evidence suggesting an episomal state. Virology. 1987;158:265-275.

10. Kirn D, Martuza RL, Zwiebel J. Replication-selective virotherapy for cancer: biological principles, risk management and future directions. Nat Med. 2001;7:781-787.

11. Kaplitt MG, Tjuvajev JG, Leib DA, et al. Mutant herpes simplex virus induced regression of tumors growing in immunocompetent rats. J Neuro-Oncol. 1994;19:137-147.

12. Goldstein DJ, Weller SK. Factor(s) present in herpes simplex virus type 1 -infected cells can compensate for the loss of the 
large subunit of the viral ribonucleotide reductase: characterization of an ICP6 deletion mutant. Virology. 1988;166:41-51.

13. Pyles RB, Thompson RL. Evidence that the herpes simplex virus type 1 uracil DNA glycosylase is required for efficient viral replication and latency in the murine nervous system. J Virol. 1994;68:4963-4972.

14. Fang ZY, Tenser RB, Rapp F. Hepatic infection by thymidine kinase-positive and thymidine kinase-negative herpes simplex virus after partial hepatectomy. Infect Immun. 1983;42: 402-408.

15. Chen SH, Cook WJ, Grove KL, et al. Human thymidine kinase can functionally replace herpes simplex virus type 1 thymidine kinase for viral replication in mouse sensory ganglia and reactivation from latency upon explant. J Virol. 1998; 72:6710-6715.

16. Petrowsky H, Roberts GD, Kooby DA, et al. Functional interaction between fluorodeoxyuridine-induced cellular alterations and replication of a ribonucleotide reductasenegative herpes simplex virus. $J$ Virol. 2001;75:7050-7058.

17. Yoon SS, Nakamura H, Carroll NM, et al. An oncolytic herpes simplex virus type 1 selectively destroys diffuse liver metastases from colon carcinoma. FASEB J. 2000;14:301311.

18. Fan H, Villegas C, Wright JA. Ribonucleotide reductase R2 component is a novel malignancy determinant that cooperates with activated oncogenes to determine transformation and malignant potential. Proc Natl Acad Sci USA. 1996;93: 14036-14040.

19. Goldstein DJ, Weller SK. Herpes simplex virus type 1induced ribonucleotide reductase activity is dispensible for virus growth and DNA synthesis: isolation and characterization of an ICP6 lacZ insertion mutant. J Virol. 1988;62:196-205.

20. Cameron JM, McDougall I, Marsden HS, et al. Ribonucleotide reductase encoded by herpes simplex virus is a determinant of the pathogenicity of the virus in mice and a valid antiviral target. J Gen Virol. 1988;69:2607-2612.

21. Yamada Y, Kimura H, Morishima T, et al. The pathogenicity of ribonucleotide reductase-null mutants of herpes simplex virus type 1 in mice. J Infect Dis. 1991;164:1091-1097.

22. Spector T, Averett DR, Nelson DJ, et al. Potentiation of antiherpetic activity of acyclovir by ribonucleotide reductase inhibition. Proc Natl Acad Sci USA. 1985;82:4254-4257.

23. Coen DM, Goldstein DJ, Weller SK. Herpes simplex virus ribonucleotide reductase mutants are hypersensitive to acyclovir. Antimicrob Agents Chemother. 1989;33:1395-1399.

24. Mineta T, Rabkin SD, Martuza RL. Treatment of malignant gliomas using ganciclovir-hypersensitive, ribonucleotide reductase-deficient herpes simplex viral mutant. Cancer Res. 1994;54:3963-3966.

25. Boviatsis EJ, Park JS, Sena-Esteves M, et al. Long-term survival of rats harboring brain neoplasms treated with ganciclovir and a herpes simplex virus vector that retains an intact thymidine kinase gene. Cancer Res. 1994;54:57455751.

26. Thompson RL, Wagner EK, Stevens JG. Physical location of a herpes simplex virus type- 1 gene function(s) specifically associated with a 10 million-fold increase in HSV neurovirulence. Virology. 1983;131:180-192.

27. Chou J, Kern ER, Whitley RJ, et al. Mapping of herpes simplex virus-1 neurovirulence to gamma 34.5, a gene nonessential for growth in culture. Science. 1990;250:1262-1266.

28. Chou J, Roizman B. The gamma 1(34.5) gene of herpes simplex virus 1 precludes neuroblastoma cells from triggering total shutoff of protein synthesis characteristic of programmed cell death in neuronal cells. Proc Natl Acad Sci USA. 1992; 89:3266-3270.
29. Robertson LM, MacLean AR, Brown SM. Peripheral replication and latency reactivation kinetics of the nonneurovirulent herpes simplex virus type 1 variant $1716 . J$ Gen Virol. 1992;73:967-970.

30. Whitley RJ, Kern ER, Chatterjee S, et al. Replication, establishment of latency, and induced reactivation of herpes simplex virus gamma 134.5 deletion mutants in rodent models. J Clin Invest. 1993;91:2837-2843.

31. MacLean AR, ul-Fareed M, Robertson L, et al. Herpes simplex virus type 1 deletion variants 1714 and 1716 pinpoint neurovirulence-related sequences in Glasgow strain $17+$ between immediate early gene 1 and the "a" sequence. J Gen Virol. 1991;72:631-639.

32. McKie EA, MacLean AR, Lewis AD, et al. Selective in vitro replication of herpes simplex virus type 1 (HSV-1) ICP34.5 null mutants in primary human CNS tumours - evaluation of a potentially effective clinical therapy. Br J Cancer. 1996; 74:745-752.

33. Todo T, Martuza RL, Rabkin SD, et al. Oncolytic herpes simplex virus vector with enhanced MHC class I presentation and tumor cell killing. Proc Natl Acad Sci USA. 2001;98: 6396-6401.

34. Meignier B, Longnecker R, Roizman B. In vivo behavior of genetically engineered herpes simplex viruses R7017 and R7020: construction and evaluation in rodents. J Infect Dis. 1988;158:602-614.

35. Wong RJ, Kim SH, Joe JK, et al. Effective treatment of head and neck squamous cell carcinoma by an oncolytic herpes simplex virus. J Am Coll Surg. 2001;193:12-21.

36. Meignier B, Martin B, Whitley RJ, et al. In vivo behavior of genetically engineered herpes simplex viruses R7017 and R7020: II. Studies in immunocompetent and immunosuppressed owl monkeys (Aotus trivirgatus). J Infect Dis. 1990; 162:313-321.

37. Advani SJ, Chung SM, Yan SY, et al. Replication-competent, nonneuroinvasive genetically engineered herpes virus is highly effective in the treatment of therapy-resistant experimental human tumors. Cancer Res. 1999;59:2055-2058.

38. Mineta T, Rabkin SD, Yazaki T, et al. Attenuated multimutated herpes simplex virus -1 for the treatment of malignant gliomas. Nat Med. 1995;1:938-943.

39. Toda M, Rabkin SD, Martuza RL. Treatment of human breast cancer in a brain metastatic model by G207, a replicationcompetent multimutated herpes simplex virus 1 . Hum Gene Ther. 1998;9:2177-2185.

40. Todo T, Ebright MI, Fong Y, et al. Oncolytic herpes simplex virus (G207) therapy: from basic to clinical. In: Maruta H, ed. Tumor-Suppressing Viruses, Genes, and Drugs. San Diego: Academic Press; 2002:45-75.

41. Cozzi PJ, Malhotra S, McAuliffe P, et al. Intravesical oncolytic viral therapy using attenuated, replication-competent herpes simplex viruses G207 and NV1020 is effective in the treatment of bladder cancer in an orthotopic syngeneic model. FASEB J. 2001;15:1306-1308.

42. Delman KA, Bennett JJ, Zager JS, et al. Effects of preexisting immunity on the response to herpes simplex-based oncolytic viral therapy. Hum Gene Ther. 2000;11:2465-2472.

43. Toda M, Rabkin SD, Kojima H, et al. Herpes simplex virus as an in situ cancer vaccine for the induction of specific antitumor immunity. Hum Gene Ther. 1999;10:385-393.

44. Sundaresan P, Hunter WD, Martuza RL, et al. Attenuated, replication-competent herpes simplex virus type 1 mutant G207: safety evaluation in mice. J Virol. 2000;74:38323841 .

45. Varghese S, Newsome JT, Rabkin SD, et al. Preclinical safety evaluation of G207, a replication-competent herpes simplex 
virus type 1 , inoculated intraprostatically in mice and nonhuman primates. Hum Gene Ther. 2001;12:999-1010.

46. Mashour GA, Moulding HD, Chahlavi A, et al. Therapeutic efficacy of G207 in a novel peripheral nerve sheath tumor model. Exp Neurol. 2001;169:64-71.

47. Hunter WD, Martuza RL, Feigenbaum F, et al. Attenuated, replication-competent herpes simplex virus type 1 mutant G207: safety evaluation of intracerebral injection in nonhuman primates. J Virol. 1999;73:6319-6326.

48. Yoon SS, Carroll NM, Chiocca EA, et al. Influence of p53 on herpes simplex virus type 1 vectors for cancer gene therapy. $J$ Gastrointest Surg. 1999;3:34-48.

49. Coukos G, Makrigiannakis A, Kang EH, et al. Oncolytic herpes simplex virus-1 lacking ICP34.5 induces p53independent death and is efficacious against chemotherapyresistant ovarian cancer. Clin Cancer Res. 2000;6:3342-3353.

50. Chahlavi A, Todo T, Martuza RL, et al. Replicationcompetent herpes simplex virus vector G207 and cisplatin combination therapy for head and neck squamous cell carcinoma. Neoplasia. 1999;1:162-169.

51. Toyoizumi T, Mick R, Abbas AE, et al. Combined therapy with chemotherapeutic agents and herpes simplex virus type 1 ICP34.5 mutant (HSV-1716) in human non-small cell lung cancer. Hum Gene Ther. 1999;10:3013-3029.

52. Advani SJ, Sibley GS, Song PY, et al. Enhancement of replication of genetically engineered herpes simplex viruses by ionizing radiation: a new paradigm for destruction of therapeutically intractable tumors. Gene Ther. 1998;5:160-165.

53. Bradley JD, Kataoka Y, Advani S, et al. Ionizing radiation improves survival in mice bearing intracranial high-grade gliomas injected with genetically modified herpes simplex virus. Clin Cancer Res. 1999;5:1517-1522.

54. Chung SM, Advani SJ, Bradley JD, et al. The use of a genetically engineered herpes simplex virus (R7020) with ionizing radiation for experimental hepatoma. Gene Ther. 2002; 9:75-80.

55. Blank SV, Rubin SC, Coukos G, et al. Replication-selective herpes simplex virus type 1 mutant therapy of cervical cancer is enhanced by low-dose radiation. Hum Gene Ther. 2002;13:627-639.

56. Heise C, Sampson-Johannes A, Williams A, et al. ONYX015 , an $E 1 B$ gene-attenuated adenovirus, causes tumorspecific cytolysis and antitumoral efficacy that can be augmented by standard chemotherapeutic agents. Nat Med. 1997;3:639-645.

57. Khuri FR, Nemunaitis J, Ganly I, et al. A controlled trial of intratumoral ONYX-015, a selectively-replicating adenovirus, in combination with cisplatin and 5-fluorouracil in patients with recurrent head and neck cancer. Nat Med. 2000;6:879-885.

58. Kirn D. Clinical research results with $d l 1520$ (Onyx-015), a replication-selective adenovirus for the treatment of cancer: what have we learned? Gene Ther. 2001;8:89-98.

59. Jorgensen TJ, Katz S, Wittmack EK, et al. Ionizing radiation does not alter the antitumor activity of herpes simplex virus vector G207 in subcutaneous tumor models of human and murine prostate cancer. Neoplasia. 2001;3:451-456.

60. Rogulski KR, Freytag SO, Zhang K, et al. In vivo antitumor activity of ONYX-015 is influenced by p53 status and is augmented by radiotherapy. Cancer Res. 2000;60:11931196.

61. Springer CJ, Niculescu-Duvaz I. Prodrug-activating systems in suicide gene therapy. J Clin Invest. 2000;105:11611167.

62. Kramm CM, Rainov NG, Sena-Esteves M, et al. Long-term survival in a rodent model of disseminated brain tumors by combined intrathecal delivery of herpes vectors and ganciclovir treatment. Hum Gene Ther. 1996;7:1989-1994.

63. Miyatake S, Martuza RL, Rabkin SD. Defective herpes simplex virus vectors expressing thymidine kinase for the treatment of malignant glioma. Cancer Gene Ther. 1997;4: $222-228$.

64. Yoon SS, Carroll NM, Chiocca EA, et al. Cancer gene therapy using a replication-competent herpes simplex virus type 1 vector. Ann Surg. 1998;228:366-374.

65. Aghi M, Chou TC, Suling K, et al. Multimodal cancer treatment mediated by a replicating oncolytic virus that delivers the oxazaphosphorine/rat cytochrome P450 2B1 and ganciclovir/herpes simplex virus thymidine kinase gene therapies. Cancer Res. 1999;59:3861-3865.

66. Todo T, Rabkin SD, Martuza RL. Evaluation of ganciclovirmediated enhancement of the antitumoral effect in oncolytic, multimutated herpes simplex virus type 1 (G207) therapy of brain tumors. Cancer Gene Ther. 2000;7:939-946.

67. Chase M, Chung RY, Chiocca EA. An oncolytic viral mutant that delivers the $C Y P 2 B 1$ transgene and augments cyclophosphamide chemotherapy. Nat Biotechnol. 1998;16: 444-448.

68. Nakamura H, Mullen JT, Chandrasekhar S, et al. Multimodality therapy with a replication-conditional herpes simplex virus 1 mutant that expresses yeast cytosine deaminase for intratumoral conversion of 5 -fluorocytosine to 5 -fluorouracil. Cancer Res. 2001;61:5447-5452.

69. Pawlik TM, Nakamura H, Yoon SS, et al. Oncolysis of diffuse hepatocellular carcinoma by intravascular administration of a replication-competent, genetically engineered herpesvirus. Cancer Res. 2000;60:2790-2795.

70. Todo T, Rabkin SD, Sundaresan P, et al. Systemic antitumor immunity in experimental brain tumor therapy using a multimutated, replication-competent herpes simplex virus. Hum Gene Ther. 1999;10:2741-2755.

71. Carew JF, Kooby DA, Halterman MW, et al. A novel approach to cancer therapy using an oncolytic herpes virus to package amplicons containing cytokine genes. Mol Ther. 2001;4:250-256.

72. Toda M, Martuza RL, Kojima $\mathrm{H}$, et al. In situ cancer vaccination: an IL-12 defective vector/replication-competent herpes simplex virus combination induces local and systemic antitumor activity. J Immunol. 1998;160:4457-4464.

73. Todo T, Martuza RL, Dallman MJ, et al. In situ expression of soluble B7-1 in the context of oncolytic herpes simplex virus induces potent antitumor immunity. Cancer Res. 2001;61: $153-161$.

74. Wong RJ, Patel SG, Kim S, et al. Cytokine gene transfer enhances herpes oncolytic therapy in murine squamous cell carcinoma. Hum Gene Ther. 2001;12:253-265.

75. Bennett JJ, Malhotra S, Wong RJ, et al. Interleukin 12 secretion enhances antitumor efficacy of oncolytic herpes simplex viral therapy for colorectal cancer. Ann Surg. 2001; 233:819-826.

76. Parker JN, Gillespie GY, Love CE, et al. Engineered herpes simplex virus expressing IL-12 in the treatment of experimental murine brain tumors. Proc Natl Acad Sci USA. 2000; 97:2208-2213.

77. Mohr I, Gluzman Y. A herpesvirus genetic element which affects translation in the absence of the viral GADD34 function. EMBO J. 1996;15:4759-4766.

78. Taneja S, MacGregor J, Markus S, et al. Enhanced antitumor efficacy of a herpes simplex virus mutant isolated by genetic selection in cancer cells. Proc Natl Acad Sci USA. 2001;98: $8804-8808$

79. Miyatake S, Iyer A, Martuza RL, et al. Transcriptional 
targeting of herpes simplex virus for cell-specific replication. J Virol. 1997;71:5124-5132.

80. Chung RY, Saeki Y, Chiocca EA. B- $m y b$ promoter retargeting of herpes simplex virus gamma 34.5 gene-mediated virulence toward tumor and cycling cells. J Virol. 1999;73:75567564.

81. Nakamura H, Kasuya H, Mullen JT, et al. Regulation of herpes simplex virus gamma (1)34.5 expression and oncolysis of diffuse liver metastases by Myb34.5. J Clin Invest. 2002;109:871-882.

82. Miyatake SI, Tani S, Feigenbaum F, et al. Hepatoma-specific antitumor activity of an albumin enhancer/promoter regulated herpes simplex virus in vivo. Gene Ther. 1999;6: 564-572.

83. Yamamura H, Hashio M, Noguchi M, et al. Identification of the transcriptional regulatory sequences of human calponin promoter and their use in targeting a conditionally replicating herpes vector to malignant human soft tissue and bone tumors. Cancer Res. 2001;61:3969-3977.

84. Alemany R, Balague C, Curiel DT. Replicative adenoviruses for cancer therapy. Nat Biotechnol. 2000;18:723-727.

85. Rodriguez R, Schuur ER, Lim HY, et al. Prostate attenuated replication competent adenovirus (ARCA) CN706: a selective cytotoxic for prostate-specific antigen-positive prostate cancer cells. Cancer Res. 1997;57:2559-2563.

86. Chen Y, DeWeese T, Dilley J, et al. CV706, a prostate cancerspecific adenovirus variant, in combination with radiotherapy produces synergistic antitumor efficacy without increasing toxicity. Cancer Res. 2001;61:5453-5460.

87. Yu DC, Chen Y, Dilley J, et al. Antitumor synergy of CV787, a prostate cancer-specific adenovirus, and paclitaxel and docetaxel. Cancer Res. 2001;61:517-525.

88. Li Y, Yu DC, Chen Y, et al. A hepatocellular carcinomaspecific adenovirus variant, CV890, eliminates distant human liver tumors in combination with doxorubicin. Cancer Res. 2001;61:6428-6436.

89. Papanastassiou V, Rampling R, Fraser M, et al. The potential for efficacy of the modified ICP $34.5^{-}$herpes simplex virus HSV1716 following intratumoural injection into human malignant glioma: a proof of principle study. Gene Ther. 2002;9:398-406.

90. MacKie RM, Stewart B, Brown SM. Intralesional injection of herpes simplex virus 1716 in metastatic melanoma. Lancet. 2001;357:525-526.

91. Anderson WF. The current status of clinical gene therapy. Hum Gene Ther. 2002;13:1261-1262.

92. Walker JR, McGeagh KG, Sundaresan P, et al. Local and systemic therapy of human prostate adenocarcinoma with the conditionally replicating herpes simplex virus vector G207. Hum Gene Ther. 1999;10:2237-2243.

93. Ikeda $\mathrm{K}$, Ichikawa $\mathrm{T}$, Wakimoto $\mathrm{H}$, et al. Oncolytic virus therapy of multiple tumors in the brain requires suppression of innate and elicited antiviral responses. Nat Med. 1999;5:881 887.

94. Wong RJ, Joe JK, Kim SH, et al. Oncolytic herpesvirus effectively treats murine squamous cell carcinoma and spreads by natural lymphatics to treat sites of lymphatic metastases. Hum Gene Ther. 2002;13:1213-1223.

95. Coukos G, Makrigiannakis A, Montas S, et al. Multiattenuated herpes simplex virus-1 mutant G207 exerts cytotoxicity against epithelial ovarian cancer but not normal mesothelium and is suitable for intraperitoneal oncolytic therapy. Cancer Gene Ther. 2000;7:275-283.

96. Kooby DA, Carew JF, Halterman MW, et al. Oncolytic viral therapy for human colorectal cancer and liver metastases using a multi-mutated herpes simplex virus type-1 (G207). FASEB J. 1999;13:1325-1334.
97. Habib NA, Sarraf CE, Mitry RR, et al. E1B-deleted adenovirus $(d l 1520)$ gene therapy for patients with primary and secondary liver tumors. Hum Gene Ther. 2001;12:219226.

98. DeWeese TL, van der Poel H, Li S, et al. A phase I trial of CV706, a replication-competent, PSA selective oncolytic adenovirus, for the treatment of locally recurrent prostate cancer following radiation therapy. Cancer Res. 2001;61: 7464-7472.

99. Coukos G, Makrigiannakis A, Kang EH, et al. Use of carrier cells to deliver a replication-selective herpes simplex virus - 1 mutant for the intraperitoneal therapy of epithelial ovarian cancer. Clin Cancer Res. 1999;5:1523-1537.

100. Yeung S, Tufaro F, Qiang D, et al. Dextran sulfate enhances the systemic delivery of oncolytic herpes simplex virus for treatment of colorectal cancer. Mol Ther. 2001;3:S390.

101. Chahlavi A, Rabkin S, Todo T, et al. Effect of prior exposure to herpes simplex virus 1 on viral vector-mediated tumor therapy in immunocompetent mice. Gene Ther. 1999;6:17511758.

102. Miller CG, Fraser NW. Role of the immune response during neuro-attenuated herpes simplex virus-mediated tumor destruction in a murine intracranial melanoma model. Cancer Res. 2000;60:5714-5722.

103. Lambright ES, Kang EH, Force S, et al. Effect of preexisting anti-herpes immunity on the efficacy of herpes simplex viral therapy in a murine intraperitoneal tumor model. Mol Ther. 2000;2:387-393.

104. Todo T, Rabkin SD, Chahlavi A, et al. Corticosteroid administration does not affect viral oncolytic activity, but inhibits antitumor immunity in replication-competent herpes simplex virus tumor therapy. Hum Gene Ther. 1999;10: 2869-2878.

105. Chen Y, Yu DC, Charlton D, et al. Pre-existent adenovirus antibody inhibits systemic toxicity and antitumor activity of CN706 in the nude mouse LNCaP xenograft model: implications and proposals for human therapy. Hum Gene Ther. 2000;11:1553-1567.

106. Burton EA, Bai Q, Goins WF, et al. Targeting gene expression using HSV vectors. Adv Drug Deliv Rev. 2001;53:155170 .

107. Wickham TJ. Targeting adenovirus. Gene Ther. 2000;7:110114.

108. Laquerre S, Anderson DB, Stolz DB, et al. Recombinant herpes simplex virus type 1 engineered for targeted binding to erythropoietin receptor-bearing cells. J Virol. 1998;72:96839697.

109. Farassati F, Yang AD, Lee PW. Oncogenes in Ras signalling pathway dictate host-cell permissiveness to herpes simplex virus 1. Nat Cell Biol. 2001;3:745-750.

110. Coffey MC, Strong JE, Forsyth PA, et al. Reovirus therapy of tumors with activated Ras pathway. Science. 1998;282:13321334.

111. Stojdl DF, Lichty B, Knowles S, et al. Exploiting tumorspecific defects in the interferon pathway with a previously unknown oncolytic virus. Nat Med. 2000;6:821-825.

112. Balachandran S, Porosnicu M, Barber GN. Oncolytic activity of vesicular stomatitis virus is effective against tumors exhibiting aberrant p53, Ras, or myc function and involves the induction of apoptosis. $J$ Virol. 2001;75:3474-3479.

113. Bergmann M, Romirer I, Sachet M, et al. A genetically engineered influenza A virus with ras-dependent oncolytic properties. Cancer Res. 2001;61:8188-8193.

114. Fu X, Zhang X. Potent systemic antitumor activity from an oncolytic herpes simplex virus of syncytial phenotype. Cancer Res. 2002;62:2306-2312. 
115. Heise C, Lemmon M, Kirn D. Efficacy with a replicationselective adenovirus plus cisplatin-based chemotherapy: dependence on sequencing but not p53 functional status or route of administration. Clin Cancer Res. 2000;6:4908-4914.

116. Coen DM, Kosz-Vnenchak M, Jacobson JG, et al. Thymidine kinase-negative herpes simplex virus mutants establish latency in mouse trigeminal ganglia but do not reactivate. Proc Natl Acad Sci USA. 1989;86:4736-4740.

117. Markert JM, Malick A, Coen DM, et al. Reduction and elimination of encephalitis in an experimental glioma therapy model with attenuated herpes simplex mutants that retain susceptibility to acyclovir. Neurosurgery. 1993;32: 597-603.

118. Chambers R, Gillespie GY, Soroceanu L, et al. Comparison of genetically engineered herpes simplex viruses for the treatment of brain tumors in a scid mouse model of human malignant glioma. Proc Natl Acad Sci USA. 1995;92:14111415.

119. Randazzo BP, Kesari S, Gesser RM, et al. Treatment of experimental intracranial murine melanoma with a neuroattenuated herpes simplex virus 1 mutant. Virology. 1995;211: 94-101.

120. Pyles RB, Warnick RE, Chalk CL, et al. A novel multiplymutated HSV-1 strain for the treatment of human brain tumors. Hum Gene Ther. 1997;8:533-544.

121. Andreansky S, He B, van Cott J, et al. Treatment of intracranial gliomas in immunocompetent mice using herpes simplex viruses that express murine interleukins. Gene Ther. 1998;5:121-130.

122. Robinson M, Liu B, Han Z, et al. ICP34.5 deleted herpes simplex virus 1 with enhanced oncolytic and anti-tumor properties: preclinical studies. Mol Ther. 2002;5:S319. 